\title{
Identidade Étnica e Recriação das Tradições entre os Migrantes de Origem Palestina no Extremo Sul do Brasil
}

\section{Denise Fagundes Jardim}

A presença de migrantes e descendentes de árabes em diversos países, realizando cursos universitários, transitando entre múltiplas localidades, tem chamado a atenção da mídia a cada dia. É como se tivéssemos descoberto um trânsito de grupos e pessoas, em especial de árabes e muçulmanos, a partir dos eventos relacionados ao terrorismo que atingiu os Estados Unidos. A multilocalidade de migrantes, em especial seu trânsito internacional, tem sido tratada como parte daquilo que caraterizaria o terrorismo contemporâneo. Destacado de seu contexto e motivações singulares, o trânsito internacional de pessoas e grupos chama a atenção e, atualmente, amedronta, pois tem amplificado sentimentos anti-semitas e racistas.

O caminho mais comum para a compreensão deste trânsito internacional reside na demonstração de que ele é uma experiência contemporânea de transnacionalismo e de diáspora. A experiência não é exclusiva de árabes e palestinos que, removidos de seu lugar de origem, permanecem transitando e buscando inserções em outras localidades. Todavia, um largo discurso sobre a experiência da diáspora não consegue englobar as situações diversas e singulares dessas migrações. Através do estudo de situações singulares, buscamos entender o que esses trânsitos representam nas relações locais e como repercutem nas trajetórias coletivas dos migrantes.

Neste artigo, apresento alguns dos mecanismos sociais que atuaram no sentido de configurar um grupo étnico. Analiso uma experiência própria a grupos minoritários a partir das situações sociais observadas na localidade do Chuí. Estabeleço nexos entre situações 'extralocais' e 'locais' que agiram no sentido de configurar um grupo étnico e puderam dar direcionalidade a fluxos que atravessavam as decisões dos 
migrantes de procedência palestina e seus filhos (a maioria nascida no Brasil) em relação aos destinos possíveis para a vida adulta e à inserção nas relações entre os 'locais'1 .

Descrever a diáspora palestina como um tipo particular de um fenômeno geral pode sugerir um certo conforto para a análise, mas não necessariamente contribui para se conhecer a diversidade de itinerários e experiências de diáspora. Tomo a diáspora palestina como um fenômeno plural. Partilho das preocupações de Edward Said (1990) quanto à impossibilidade de tratá-la como unívoca, ou como um caso particular de um tipo geral ${ }^{2}$. A unidade imputada às trajetórias diversas dos palestinos inscreve no problema de pesquisa a tentativa de recuperar alguma 'fidelidade a tradições'. Tal perspectiva implica uma redução que, reiterando um certo orientalismo, busca uma 'alma árabe' entre aqueles que migram. Aos migrantes é dirigido o pressuposto de que suas tradições seriam residuais, sobrevivências de um momento anterior (em que estariam mais completas), e que teriam sido deturpadas durante o processo migratório visando a assimilação aos nacionais.

No início do trabalho de campo, buscava entender a grande concentração de migrantes de origem árabe residentes em cidades de fronteira internacional ${ }^{3}$. Chamava-me a atenção a presença de migrantes no Chuí, pois em uma área considerada como de segurança nacional, a presença de estrangeiros é alvo de constante vigilância por parte do poder público. Para entender a ocupação do Chuí, e o que fazem os migrantes na localidade, é necessário perceber o grande crescimento das atividades comerciais desde os anos 70 . As atividades comerciais se beneficiaram da implementação de equipamentos que encenam a presença do poder público e, portanto, da presença do Estado. No Chuí, os equipamentos do poder público - serviços de telefonia, abastecimento de água e luz, bancos públicos, escolas e postos de saúde - permitiram transformar o 'local' em um símbolo do 'nacional'.

A urbanização como recurso de demarcação de fronteira não foi implementada exclusivamente no Chuí, mas em outras cidades contíguas ao Uruguai. Embora no Uruguai as ações no sentido de equipar as cidades de fronteira sejam mais antigas, visavam eliminar as indefinições e inscrever uma descontinuidade que não é identificada em nenhuma barreira natural ${ }^{4}$.

Há inúmeros desdobramentos na cena local em que a afirmação da singularidade do município é associada a símbolos nacionais, e que versam também sobre sua bi-nacionalidade. Na afirmação da singularidade do recém criado município (desde 1996), a presença de 'estrangeiros' permitira afirmar um 'multiculturalismo' e, desse modo, veicular noções positivas sobre a presença massiva de estrangeiros nas relações locais. Há momentos críticos em que a cidade é colocada sob suspeita, pelos jornais e noticiários regionais e nacionais, e figura como uma área de ações ilegais e de contrabando. Nas campanhas políticas locais, os candidatos tratam a cidade como uma síntese do Brasil e do multiculturalismo. Os 'estrangeiros' passam a ser incorporados simbolicamente como 
parte do mundo social, relacionados aos 'locais'. Nessas situações, são produzidas versões e interpretações que tendem a singularizar o município de fronteira e permitir a incorporação simbólica dos potenciais estrangeiros. A classificação se torna extensiva a todos os moradores que vieram 'construir' o Chuí.

A pesquisa desenvolvida a partir da cidade do Chuí permitia conhecer tanto as relações sociais na localidade, quanto as experiências que tinham conduzido os migrantes para as localidades de fronteira. Assim, os migrantes de procedência árabe atuam no comércio local, têm supermercados e lojas que revendem aos uruguaios os produtos da indústria brasileira. Constituem um segmento que consegue ter liquidez nas suas atividades econômicas, algo escasso em uma região de grandes proprietários rurais, de granjas e de mercado imobiliário pouco dinâmico. Seus fornecedores estão em São Paulo e Santa Catarina, estados em que residiram nos primeiros tempos de Brasil.

Para este trabalho foram entrevistadas diretamente 70 pessoas (ver J ardim 2001). O universo de pesquisa abrange cerca de dez famílias, assim definidas mais de acordo com seus critérios do que por uma indicação de correspondência a unidades domésticas. Poderíamos estimar que a indicação de 'uma família' envolve cerca de três unidades domésticas. Durante um ano, de abril de 1996 a maio de 1997, centralizei meus esforços no Chuí e, nos anos seguintes, entrevistei os filhos de migrantes que estivessem dispostos a conceder entrevistas, fato que estendeu meus contatos ao longo desses anos a outras cidades da região Sul do Brasil.

A grosso modo, poderia dizer que iniciei um estudo sobre a trajetória de 'migrantes' de origem árabe ou palestina, e sobre um grupo predominantemente muçulmano. Essas categorias genéricas, entretanto, impunham uma realidade a priori ao trabalho de campo. Durante o trabalho de campo buscava compreender a coexistência de uma diversidade de procedências e de itinerários de chegada ao Chuí. Estava interessada, portanto, na diversidade, e em como unidades sociais eram produzidas pelos entrevistados reduzindo a discrepância.

Minhas observações e entrevistas ocorreram nas lojas; muitas delas eram suas residências ou de parte da família. As unidades domésticas pareciam sempre umas conectadas a outras. A parentela poderia ter três ou quatro lojas com parentes ocupados nas diversas atividades empreendidas pela família. Além disso, em que pesem as diferenças entre migrantes quanto à entrada no Brasil, as estratégias de inserção e tempo de permanência no Chuí, em muito aspectos, eram comuns.

É comum aos migrantes que estendam suas redes de relações de trabalho e familiares para outras cidades, em especial cidades vizinhas como Santa Vitória do Palmar, Pelotas, Rio Grande, cidades do interior do Rio Grande do Sul. Há uma intensa visitação e relações entre as famílias migrantes nas cidades do Sul do Brasil.

Há um uso generalizado de noções genéricas pelas procedências diversas de países no Oriente Médio. A identificação como palestino e árabe, utilizada pelos entrevistados, remete a uma história de longa duração dessas 
classificações e a situações extralocais. As identificações de nacionalidades não são exclusivas ou invenções do campo observado 5 . São denominações que carregam noções de jus solis e jus sanguinis, que freqüentam outros espaços e exprimem tensões sociais sobre a possibilidade de portar passaportes nos países de origem e destino.

No campo observado, essas noções operam como classificações úteis porque traduzem divisões no mundo social e dirigidas às relações locais. Permitem-nos pensar sobre sua inflexão, sobre os usos possíveis da noção de origem, associada a temas e a divisões de mundos sociais, ou seja, o uso da 'origem' como forma de classificação social.

O uso de denominações genéricas e a multiplicidade de procedências e tempos no Brasil compõem o cenário de meu trabalho de campo. Seria difícil falar sobre as autodenominações do grupo pesquisado, como árabes, palestinos, migrantes, sem freqüentar as tensões e negociações simbólicas que envolvem tais denominações na localidade. Da mesma forma, as práticas religiosas relacionadas ao Islamismo variavam. A maioria dos entrevistados é muçulmana, seja migrante ou filho de migrante. Não há uma mesquita, mas uma sala de oração e um cemitério exclusivo para os muçulmanos. Tais indícios levavam-me a perguntar sobre determinadas cisões e divergências produzidas localmente, evidenciadas nas diferentes possibilidade de conduzir a "comunidade" nas relações locais, e sobre a pertinência ou não de fazer uso da religião como forma de comunização. Na época, não existia uma liderança religiosa permanente, o que não impedia as práticas confessionais e o uso do cemitério islâmico. Porém, diferentemente de outras situações relacionadas a grupos minoritários, a religiosidade não era um dos recursos utilizados para sublinhar a existência de uma coletividade singular com espaços exclusivos.

Quando cheguei a campo, no início dos anos 90, os migrantes se referiam a um 'nós' em comum através da identidade palestina. Como diziam, "aqui é tudo palestino". Nesse jogo de forças enfatizavam uma singularidade e propunham uma 'totalidade'. Cabia perguntar quais os processos sociais que tornaram essa classificação conhecida e disponível, e como ela operava, incluindo e excluindo sujeitos nessa denominação genérica. Além de ser uma classificação 'útil' para pensar as relações sociais 'localmente', centrei meus esforços na compreensão de aspectos que possibilitaram a ampla circulação dessa forma genérica de classificação nas relações locais. Quais os processos sociais que fizeram circular e tornar pertinente essa classificação como uma divisão do mundo social? Quais os processos que difundiram e tornaram essa denominação algo genérico? De que maneira as noções genéricas de "palestino" puderam encompassar a multiplicidade de narrativas sobre a origem? Porque a identificação como oriundos da cidade de Ramallah ou como jordanianos não era mais interessante do que a denominação como palestinos? Em parte, evidenciava-se que a denominação era uma classificação útil para identificar "estabelecidos" entre os locais e "recém-chegados" nas relações com os locais. 
Os migrantes de primeira geração chegaram no Brasil no final dos anos 50 e no Chuí nos anos 70, depois de um longo percurso pelas cidades no interior do Brasil. Outros migrantes residentes, também uma 'primeira geração' vinda ao Brasil e ao Chuí, estavam situados na chamada Rua J enin e chegaram nos anos 80 na localidade. Eles usufruem de uma rede de relações que os traz diretamente para trabalhar como empregados das grandes lojas dos patrícios. Com os patrícios já estabelecidos conseguem seu primeiro trabalho e a possibilidade de se tornarem arrendatários de uma das pequenas lojas na Rua J enin. Nessa rua podem iniciar suas atividades. É um lugar de passagem para outras possibilidades de trabalho no Brasil; a mais desejada é se tornar um 'dono' de seu próprio negócio ${ }^{6}$.

Na primeira parte de minha etnografia, buscava inspecionar os relatos dos migrantes, as trajetórias individuais, e entender quais as situações que os levaram a migrar. Quais eram seus recursos e as estratégias traçadas que possibilitaram a viagem para o Brasil, e por que o Brasil. Percebia uma multiplicidade de situações que estavam sendo encompassadas por noções que produziam generalizações sobre o significado da situação do 'migrante', e que remetiam a trajetória do 'mascate' (ver J ardim 1999).

$\mathrm{O}$ ato de 'mascatear', vender produtos de porta em porta, carregar a mala de produtos, continha dois aprendizados. O primeiro aprendizado revelava o ofício de mascate como uma aquisição da migração. Nas entrevistas, revelavam quais eram suas possibilidades de trabalho na aldeia de origem e o que sabiam fazer; referiam-se também a um leque variado de motivações que os conduziam à migração. Muitos já tinham saído da unidade camponesa, viviam nas aldeias de refugiados e alguns tinham ingressado no exército da J ordânia. Outros buscavam sair de campos de refugiados usando expedientes bastante variados para conseguir passaportes. Ao narrar sua iniciação na atividade de mascate e o aprendizado do ofício com patrícios e familiares, forneciam informações sobre as dinâmicas familiares que os conduziram e os apoiaram na imigração.

A unidade de seu itinerário no Brasil era percebida, inclusive pela platéia constituída por outros migrantes, através da experiência de mascatear. Uma experiência que os recém-chegados não tinham realizado. As narrativas colocavam em circulação a possibilidade de redução dos diversos itinerários a uma unidade. Os entrevistados eram tomados como exemplos da migração mais antiga, e suas narrativas sobre o aprendizado do mascatear uma comprovação de antigüidade. Ao mesmo tempo que discorria sobre os "primeiros tempos", o narrador tecia seu relato nas suas lojas diante de uma platéia de comerciantes (árabes recém-chegados na cidade) ou familiares.

Muitas vezes registrei os meus interlocutores, a platéia interessada nas minhas entrevistas, retomando um relato produzido em uma situação coletiva e tratando-o como um relato genérico sobre os "primeiros" na localidade. As narrativas eram tomadas como um relato dos "mais velhos" na cidade e indicavam uma aproximação, maior ou menor, do interlocutor com aquele que era tido e visto como o migrante já "estabelecido" nas relações locais” . 0 
relato era mais do que uma informação para o trabalho de campo: permitia ampliar a circulação de histórias tidas como exemplares da trajetória dos migrantes "mais antigos" em relação aos "recém-chegados". Ajudava a refletir coletivamente sobre quais as possibilidade de sucesso que podiam esperar ao estabelecer uma loja no Chuí, um assunto que interessava a todos.

\section{I}

Diferentes ações coletivas indicavam as formas de inserção empreendidas nas relações locais, ora enfatizando espaços de exclusividade, ora investindo na inserção entre os 'locais', fazendo uso da identidade étnica. Na década de 80 , os esforços coletivos sublinhavam a coletividade árabe, marcando sua singularidade e exclusividade. As ações resultaram na construção de um prédio com sala de reuniões para duzentas pessoas para ser a sede do clube árabe. Anos depois, o prédio era descrito como abandonado. A situação revelava dois momentos e a cisão entre migrantes sobre os caminhos possíveis para inscrevê-los entre os locais. O 'abandono' do clube não significava que os seus principais agentes estivessem fora de atividade. Pelo contrário, estavam imersos nas redes de relações em lugares de poder entre os 'locais'. Ou seja, durante o campo (iniciado em 1996), parecia que a 'estratégia' de inserção tinha mudado. Certas divergências entre migrantes foram acirradas no final dos anos 80, no momento de efervescência e configuração de uma comunidade de origem que resultaram em cisões entre aqueles que fundaram o clube árabe. As ações coletivas visavam inscrevê-los entre os locais, mas novas situações recolocavam o tema da identidade étnica. A política partidária exigia a necessidade de refletir sobre a origem com certo distanciamento, percebendo que um dos custos do reconhecimento dessa origem era o de eternizá-los como estrangeiros.

Conduzindo minhas entrevistas em campo tive acesso aos documentos que permitiam recompor os acontecimentos nos anos 80 no Chuí. Nessa época, os massacres em cidades palestinas eram tão comentados na cidade do Chuí quanto o reconhecimento da OLP e de Arafat como legítimo representante do Estado Palestino na ONU. Diferentes iniciativas coletivas foram empreendidas na localidade, exigindo a participação dos migrantes e não-migrantes, em vista da comemoração do reconhecimento do Estado Palestino pela ONU. As ações coletivas também serviam para veicular informações sobre fatos internacionais, palestras foram proferidas, monumentos eram inaugurados na localidade e, finalmente, os jovens filhos de migrantes eram solicitados a participar e a fazer algum tipo de formação política para falar em público, aprendendo sobre a história dos conflitos na palestina, sua gênese e explicações históricas. O escritório da OLP em Brasília fomentou a criação da sanaud, primeiramente em três localidades no Brasil, a primeira delas foi no Chuí. Nos cursos de formação, incentivavam a formação de 
lideranças étnicas, que estavam sendo orientadas para participar da vida pública, prioritariamente os filhos de migrantes ${ }^{8}$.

No início dos anos 90, outras ações coletivas foram empreendidas por filhos de migrantes. Um time de futebol chamado de "Central Palestino" fora criado por esses migrantes no Chuy uruguaio. De diversas formas públicas, os sujeitos investiam seu tempo nas ações coletivas que ajudavam a dar contornos a uma 'coletividade árabe'. As ações visavam apoio e divulgação da causa palestina nas relações e instituições locais. Assim, inscreviam sua existência nas relações locais utilizando-se de referências extralocais relativas à identidade palestina. Colocavam em circulação noções de nacionalidade e de 'origem' e, ao mesmo tempo, permitiam dialogar e reelaborar significados da pecha de "turco", atribuída e usada para classificar genericamente os migrantes que atuam no comércio.

As atividades exigiam a participação de uma 'coletividade' e, através de fatos contemporâneos, o tema comum eram os destinos coletivos. De fato, para certas famílias residentes no Chuí, era o momento de pensar na possibilidade de escolarização no segundo grau para seus filhos nascidos no Brasil. A continuidade da escolarização no ensino de segundo grau no 'lado brasileiro' implicava um esforço da família para continuar os estudos em Santa Vitória do Palmar (a meia hora do Chuí) ou mudar-se para outra localidade. Se no Chuí não havia opções, se não no 'lado uruguaio', as opções indicavam a necessidade de criar alternativas de residência temporária para os estudos dos filhos. Uma das opções era a de residência temporária com algum parente na terra natal do migrante.

Os entrevistados ressaltam esse período como um tempo em que as caixas registradoras estavam repletas de dinheiro e as lojas cheias de uruguaios. A agitação local colocava em circulação um campo de possibilidades mais amplo para os filhos de migrantes do que as relações travadas no Chuí. Na mesma parentela, alguns irmãos investiram em cursos superiores, enquanto outros declinaram dessa possibilidade, permanecendo no trabalho das lojas, em função da avaliação de boas perspectivas no comércio local.

Antes das ações coletivas produzidas no Chuí, determinadas famílias de migrantes puderam planejar um retorno temporário para a Palestina, onde acabaram buscando alternativas de escolarização e aprendizado do idioma árabe, revitalizando os laços com parte da parentela que residia no Oriente Médio. Alguns laços familiares já tinham sido atualizados em viagens pontuais, para cumprir a peregrinação a Meca, ou recebendo algum parente no Chuí (vindos do Oriente Médio). A perspectiva de escolarização em árabe era uma extensão da possibilidade já aberta de 'retorno', efetuada por alguns migrantes, e coincidia com as viagens programadas para visitar os parentes e apresentar seus filhos depois de vinte anos de residência no Brasil.

As famílias migrantes no Chuí investem na ampliação da competência lingüística. O interesse pelo idioma árabe é uma confluência de interesses entre as gerações que, nesse caso, permitiu recuperar de forma positiva o 
tema da origem árabe. A princípio isso significa, entre outras coisas, corresponder às expectativas da família de orientação e, em especial, do pai migrante. No Chuí há a possibilidade de trabalho e de ampliação de competências em mais um idioma, o espanhol. Em parte, isto explica o fato de os filhos de migrantes terem aderido ao aprendizado de um terceiro idioma, o árabe, pois já dominavam o português e o espanhol sem misturá-los.

Dessa maneira, a difícil comunicação reconhecida entre pais e filhos e indicada no domínio de idiomas diferentes na família sofria uma alteração. Era uma possibilidade dos filhos virem a falar o árabe, como os pais, pois nem todos os filhos de migrantes falavam árabe. As viagens permitiam ampliar possibilidades de aprender 0 idioma árabe - tão comum nos encontros e na sociabilidade de rua, mas que não estava acessível a todos os filhos de migrantes - e de atualização dos laços familiares. Tanto os laços familiares quanto o aprendizado do idioma árabe permitiam revitalizar noções fundamentais sobre a origem comum e sobre a unidade da 'família árabe', recuperando idéias de laços primordiais e da continuidade dos laços familiares rompidos pela experiência migratória. As viagens de 'retorno' disponibilizavam os sujeitos ao tema da origem como uma experiência inalienável e propiciavam opções novas para a vida adulta.

A inserção nas atividades e iniciativas locais (Sanaud e Central Palestino) lembravam um engajamento anterior ocorrido nas viagens e visitas entre famílias. Essas iniciativas eram propostas e intermediadas pelos migrantes e pelo clube árabe, em outras palavras, por seus pais. Dessa vez, fazia-se uma atualização, e identidade étnica se referia a algo mais atual. A novidade era a referência a uma nacionalidade em risco, sobre a nacionalidade a ser recuperada. Os laços de sangue e o domínio do idioma mantiveram um estreito diálogo com as versões difundidas pelo escritório da OLP quanto à definição de nacionalidade palestina. Na carta de emancipação da Palestina há a referência da linha paterna de ascendência como a definição do cidadão palestino.

No campo observado, o uso da denominação de palestinos é contemporânea ao reconhecimento da ONU do direito a um Estado Palestino e da representatividade de Arafat como chefe de Estado, mas também é contemporânea às atividades coletivas que tentam inscrevê-los nas relações de poder no Chuí. Esses são fatos que ajudaram a colocá-los no mapa, fundamentalmente, em um mundo social referido a situações extralocais, e também no mapa das relações com grupos locais.

A referência a uma nacionalidade foi sendo configurada não só pelo reconhecimento dos laços entre as famílias migrantes com o território de origem, mas por suas atualizações possibilitadas pela viagens que efetuaram. Os engajamentos nas viagens e, posteriormente, as ações coletivas, traçaram a possibilidade de revitalizar a pertinência da origem e a atualidade da tradição. As viagens acabam produzindo efeitos não esperados para os filhos, pois já tinham um domínio sobre as noções de origem como sua ou de sua família, identificando gradações e distâncias com a família árabe, palestina e com as tradições. As viagens acabam produzindo uma memória 
coletiva que todos dominam, ou porque fizeram alguma viagem ou porque a farão, ou porque conhecem outros relatos de viagem. Através das viagens, adquirem o domínio tanto sobre a 'família árabe' e seus possíveis modelos e diferenças de acentos do idioma - seja porque aprendido nas viagens da volta da família para a Palestina, seja porque falado e aprendido na cidade, que continua a receber novas levas de migrantes muçulmanos que usam basicamente o idioma árabe em suas relações, através dos quais inspecionam os vários acentos (usos) na localidade ${ }^{9}$.

A identidade palestina foi disponibilizada através de agentes interessados, em especial as representações da OLP e os participantes do Sanaud e do time Central Palestino. As ações visavam diretamente os filhos de migrantes (que potencialmente poderiam se definir como brasileiros) e acabaram envolvendo-os também por ser uma possibilidade de inclusão na vida pública local. Alguns dos filhos de migrantes já tinham efetuado suas visitas entre famílias e dominavam perfeitamente o idioma árabe, e alguns deles tinham efetuado viagens especialmente para o seu aprendizado.

O escritório da OLP os contata através do clube árabe e direciona suas atenções aos filhos de migrantes nascidos no Brasil. De diversas maneiras, visavam incluí-los de forma ativa na veiculação da 'questão palestina'. Quando a OLP busca os filhos de palestinos para participar da Sanaud, nos anos 80, encontra uma primeira geração de nascidos no Brasil que já tinha efetuado a viagem da volta com os pais (ver Oliveira 1994). Fazia dois anos que tinham passado por uma experiência direta com a terra natal dos pais e com noções genéricas sobre a 'família árabe'. Dominavam o idioma árabe e estavam previamente disponibilizados com o reconhecimento de sua 'origem' para ingressar nessa atividade. Da mesma forma que outras propostas, essa seguia o mesmo percurso: era intermediada pelo clube árabe e, portanto, mais uma vez, pelos pais migrantes.

As viagens internacionais ocasionaram uma revitalização do idioma étnico e viabilizaram os nexos entre o étnico e o nacional, inscreveram-se nas experiências individuais enquanto instrumentos que permitiam pensar uma "comunidade imaginada". Não podemos esquecer que a vitalidade desta identificação pela nacionalidade não está alheia ao próprio lugar em que buscam se estabelecer, uma cidade entre Uruguai e Brasil, onde há sempre um potencial estrangeiro em suas relações e a referência a 'nacionalidades'.

Ao mesmo tempo, os fatos 'extralocais' acabam dando uma direção positiva para os destinos dos filhos de migrantes, ampliando suas possibilidades para a vida adulta e dando uma outra dimensão aos impasses e conflitos entre pais e filhos sobre seus projetos possíveis para a vida adulta ${ }^{10}$. Através dessas situações sociais, que adensam fatos 'extralocais' e 'locais', podemos perceber a produção de uma 'coletividade' que usufrui de noções genéricas sobre a origem. 
Tomando-os como um grupo minoritário, podemos perceber o que fazem os palestinos no Chuí e quais os jogos identitários prioritários em relação à acusação de turco e à atividade de mascate que aprenderam no Brasil. A sociedade brasileira parece ter traçado alguns itinerários que os migrantes devem cumprir, mesmo aqueles chegados no final dos anos 50. Eles tiveram que se adequar a uma imagem já produzida, como turcos, e aos caminhos de inserção já consagrados por outros na atividade de 'mascate'. Eles eram vistos conjuntamente como oriundos de uma 'mesma raça', 'mesmo território' e por dominarem o mesmo idioma.

Diferentemente de outros árabes no Brasil, meus entrevistados são muçulmanos e não fizeram de sua singularidade religiosa algo fundamental para delinear uma comunidade. Note que a bibliografia disponível sobre palestinos em Berlim mostra que a religião muçulmana fornecia os elementos para uma noção de 'comunidade'.

Embora os migrantes tenham visitas constantes de representantes religiosos (os cherks), o idioma dessa comunização nas fronteiras entre Brasil e Uruguai (e no Rio Grande do Sul) é de outra ordem - a nacionalidade - e tende a buscar referências que propiciem uma melhor inserção nas relações com grupos e mesmo com patrícios na sociedade local e binacional. No entanto, uma explicação que remete a uma região de origem não esgota as explicações sobre o uso do idioma da nacionalidade como eixo identitário. Existem ações que reiteram a singularidade.

Como um grupo minoritário, utilizam-se de referências globais. Como indicaram Thomas \&Znaniecki (1974) sobre os poloneses nos Estados Unidos, as referências globais ajudaram a produzir uma solidariedade étnica. Como os poloneses, tanto o treinamento de lideranças quanto as associações de cunho nacionalista (com conexões extralocais) produziriam um duplo benefício, tanto para os poloneses americanos na América quanto para os que voltaram para a Polônia. Ambas as 'escolhas' foram propiciadas por um sentimento de patriotismo e nacionalismo ${ }^{11}$. Da mesma forma, o percurso dos migrantes palestinos no sentido de instaurar iniciativas coletivas apóia-se em uma dupla referência, a local e a extralocal, a atual e a originária. Em especial, se readequarmos a noção de nacionalismo a que é referida por Gellner (1983), poderemos perceber a potencialidade da referência a uma origem nacional como forma de definir grupos, especialmente quando ela aparece em risco, como no caso dos palestinos. $\mathrm{O}$ uso da referência à nacionalidade dinamiza também as relações locais.

Na criação de associações e iniciativas coletivas nos anos 80 está em jogo aquilo que Norbert Elias (1994) toma como um paradigma empírico das relações entre grupos, suas relações de poder: há, por um lado, uma tendência de um grupo estigmatizar outros, no sentido de disputar posições de poder (local); de outro, é uma produção de auto-imagem que produz a diferença. Ao invés de serem classificados conjuntamente como 
estrangeiros, percebem-se como uma parte. Uma parte que sublinha a origem palestina, redirecionando a acusação de provisoriedade a outros (potencialmente os recém-chegados na ruaJ enin), o que dinamiza os jogos de acusações e relações de poder locais. Vistos conjuntamente como estrangeiros, o tom empregado é acusatório, especialmente no caso de uma fronteira internacional, em uma cidade contígua a outra na fronteira seca entre Uruguai e Brasil. 0 jogo de diferenciações entre "estabelecidos" e "outsiders" permite explicar a vitalidade da referência à origem (estrangeira) do migrante, sendo relida por um outro jogo identitário, outros jogos de poder, redirecionando o tom acusativo e excludente que permeia as relações com grupos locais. Deixar de ser visto como estrangeiro e espúrio e passar a ser visto como local é uma questão pertinente para a inserção do migrante como um comerciante confiável aos seus pares.

O uso de referências a um repertório de origens é um idioma que permite conhecer como traçam suas relações com a sociedade local e que o fazem no sentido de estabelecer fronteiras simbólicas a uma "comunidade imaginada". No Chuí essa 'comunidade árabe' ou 'palestina' aparece produzida e refeita em meados dos anos 80 e início dos 90. Essa 'comunidade' a que todos se referem e que, durante o trabalho de campo, revelava-se como um registro de uma memória coletiva sobre os anos 80 e início dos anos 90 era, para os entrevistados, algo a um só tempo impalpável na atualidade (durante o trabalho de campo em fim dos anos 90) e reveladora de suas cisões e diversidade local.

No Chuí encontramos todos os eventos que ajudaram a produzir a existência de uma "comunidade imaginada". São migrantes oriundos do Oriente Médio que se percebem como uma comunidade de origem árabe, em sua maioria vinda da região de Ramallah, referindo-se não só por uma alusão a uma aldeia (palestina), mas à identificação de um sotaque, um idioma árabe falado no interior. Portanto, a um só tempo remetem a uma referência de origem cujas bases são lingüísticas e de procedência de uma mesma aldeia. A reelaboração dessas referências como 'palestinas' dependeu da presença de agentes interessados e de um terreno pleno de conflitos, em especial de divergências revestidas em diferenças de gerações que receberam essas novas informações e agentes e reconfiguraram o étnico, a aldeia, a 'família árabe' em nacional, sublinhando sua atualidade.

Se as iniciativas coletivas fazem parte da memória recente de uma 'coletividade árabe' predominantemente palestina produzida nos anos 80 e 90, as viagens permanecem como importante expediente que atualiza a referência à origem, produzindo mais do que uma solidariedade étnica na localidade ou um caminho postergado de volta. As viagens ampliaram o campo de possibilidades para traçar destinos para as famílias e para seus filhos brasileiros e, ao mesmo tempo, atualizaram a pertinência da origem como um idioma de identidade coletiva.

As iniciativas coletivas empreendidas no Chuí no final dos anos 80 estabeleceram cumplicidades entre famílias através da solidariedade de gerações. O time de futebol, as carreatas comemorativas e passeatas em 
apoio ao povo palestino reforçaram a solidariedade traçada na 'mesma geração'. Se a longo prazo contribuíram para produzir um engajamento nos temas relacionados à 'origem' e a recriação de tradições, fizeram-no reforçando uma solidariedade geracional, uma clivagem entre gerações de migrantes, e utilizando-se da referência à nacionalidade palestina. Devemos lembrar que, cronologicamente, nos relatos dos jovens entrevistados as viagens internacionais e as visitas entre parentes são anteriores à participação no sanaud ou nas iniciativas coletivas dos anos 80. Elas antecederam e disponibilizaram os filhos nascidos no Brasil a todas as outras ações coletivas e ao reconhecimento de tradições, entre elas a participação no circuito de festas de casamento e a adesão aos casamentos 'arranjados' pelos pais com os filhos de patrícios ${ }^{12}$.

As viagens mediaram os conflitos entre gerações ${ }^{13}$. Os jovens demonstravam sua ambivalência entre aderir às propostas dos pais para produzir alternativas de trabalho e quanto à vida afetiva, e a possibilidade de criar alternativas às disponibilizadas pela família. As viagens e as festas de casamento ajudavam a fazer coincidir projetos díspares e redirecionavam os fluxos que poderiam ser apenas conflitos produtores de cisões na família' ${ }^{14}$.

As viagens atuaram como facilitadores de outras propostas familiares, de inserções em entidades e de iniciativas coletivas nos anos 80 e início dos 90 , direcionando fluxos e permitindo a atualização de tradições. 0 trabalho de campo possibilitou averiguar como estas propostas de viagem surgiam entre os familiares. $\mathrm{O}$ apoio ou 'patrocínio' de uma viagem estava relacionado não só a um funcionamento peculiar da família árabe, mas a um contexto mais amplo de relações dessas famílias de migrantes com os 'locais'. Dessa maneira, permitiam uma identificação dos comerciantes com a origem palestina e não com a atribuição de "turcos".

Como registra Turner (1974), a viagem dá ao sujeito, através deste ato de decisão pessoal, a consciência da distância e da ruptura. Através das viagens e visitas entre famílias, os migrantes e seus filhos puderam dar direcionalidade a fluxos que atravessavam e exigiam decisões sobre as perspectivas possíveis para seus destinos na localidade e sobre a vida adulta de seus filhos. Em suas primeiras viagens, percebem a distância ocasionada pela migração. Na geração do migrante, as viagens quase sempre estarão relacionadas a peregrinação a Meca e, deste modo, a viagem explicitará o sentido ritual, expressando liminaridades e instaurando um momento de communitas. As peregrinações reiteram o intervalo entre dois distintos mundos ou temporalidades. Para os migrantes, essa viagem visa recuperar o descontínuo, um afastamento de vinte anos. Restabelecem a consciência de participar de uma larga totalidade, a dos peregrinos muçulmanos.

Como uma obrigação religiosa muçulmana, algumas famílias as empreenderam nos anos 80. A experiência tem sido largamente disponibilizada e desejada por migrantes e filhos de migrantes que residem no Chuí e em outras localidades no Sul do Brasil. Podemos dizer que as visitas e viagens atuaram para além da obrigação religiosa, colocando em circulação e dando vitalidade ao tema da origem. Ao mesmo tempo, como uma obrigação e uma 
promessa, a viagem atuara no sentido de recompor experiências diversas e produzir uma coletividade sobre experiências migratórias díspares. Do mesmo modo, as ações coletivas contribuíram para reduzir a discrepância entre trajetórias individuais eas dinâmicas familiares. Assim, tanto a participação nos clubes quanto o sanaud revelavam as diferenças de expectativas entre gerações e as solidariedades geracionais 'nas' famílias de migrantes.

Atualmente, as viagens para conhecer parentes ou aprender o idioma árabe estão no horizonte de possibilidades dos jovens filhos de migrantes no Chuí, recursos que tiram benefício da multilocalidade das relações familiares. Embora para alguns jovens a viagem não seja exatamente uma viagem de retorno e sim a sua primeira viagem, seus relatos demonstram o modo como foram iniciados na origem árabe, de forma proporcionada e planejada pela família. A identidade de origem foi estendida à possibilidade de identidade nacional.

As viagens se tornaram um horizonte possível a ser realizado, desejado e conhecido através da experiência de um primo ou de alguém de uma mesma geração. É um assunto partilhado nas visitas entre famílias no Chuí. Por parte dos filhos, poderiam ser interpretadas como peregrinações voluntárias. Engajar-se nas viagens demanda o envolvimento em um ritual coletivo de preparação, planejamento da jornada. Um ato pessoal mas que é relido coletivamente, como um momento de passagem e iniciação voluntária, iniciação nos costumes e no idioma. Além de ser uma experiência com o diverso, parte do estranhamento que remete a uma familiaridade com a origem é inicialmente uma experiência direta de estranhamento com a família 'árabe', com aquilo de que deveriam fazer parte.

Se através das viagens os migrantes conseguiram no início dos anos 80 recriar a pertinência da origem entre os filhos nascidos no Brasil, esses migrantes convivem com outras famílias migrantes que transitam e participam de suas relações e com outras que trabalham na cidade e que efetuam viagens entre parentes. A prática tem mediado as relações entre gerações nas famílias migrantes, mas também é tema constante para melhor definir os migrantes "estabelecidos" e os "outsiders" na localidade. Na rua J enin, tanto quanto em outras relações, há uma prática comum de inspecionar sobre as chegadas e saídas de migrantes. Ocorrem visitas para apresentar os recém-chegados ou para mostrar fotos e relatar suas viagens. As visitas podem referir ou servir como possibilidade de trazer parentes e amigos para as relações sociais locais, ou para ampliar a rede de relações entre migrantes e entre localidades.

As viagens colocam em movimento uma série de anseios e possibilidades, entre elas a de contornar conflitos entre gerações nas relações familiares, em especial alguns conflitos entre pais e filhos, entre recém-chegados e estabelecidos, abrindo novas perspectivas para conduzir as escolhas profissionais e afetivas. As visitações e viagens tem ampliado um circuito muito apreciado por pais e filhos, os casamentos árabes.

As festas de casamento são uma expressão das conexões entre as famílias migrantes, pois implicam visitas 
a longa distância. Reúnem migrantes de localidades diferentes e colocam em circulação uma solidariedade na geração dos filhos dos migrantes, muitas vezes traduzida na solidariedade entre primos. Nessas ocasiões expressam aquilo que reconhecem como parte das 'tradições', os rituais que prescrevem (o ritual da hena) e as noções de casamentos arranjados entre primos como 'casamentos corretos'.

As noções de 'tradições' expressas nas festas de casamentos são disponibilizadas e postas em circulação para essa 'geração' de filhos de migrantes. É a possibilidade direta de conhecer e de se reconhecer nas tradições, bem como de vir a ingressar nessa rede de solidariedade geracional participando de um casamento árabe ou festa de noivado, ingressando no circuito dos desposáveis ${ }^{15}$.

Como indicamos, diferentes situações sociais contribuíram para configurar uma comunidade imaginada, reduzindo discrepâncias e permitindo criar certezas sobre a identidade palestina e os árabes no Chuí. Isso não significa que suas trajetórias díspares tenham se acomodado em vista a sua inscrição como uma 'comunidade' relevante nas relações locais. É importante ressaltar a multiplicidade de caminhos possibilitados por esses fenômenos observados localmente. Eles atravessam as relações sociais e as famílias migrantes. Portanto, se podemos perceber no Chuí todo um trabalho de inscrição das famílias na localidade como um grupo minoritário, da mesma maneira podemos vislumbrar outros itinerários abertos aos filhos de migrantes e para os recém-chegados na localidade, para além das relações locais, como parte da experiência de um grupo minoritário.

Outros itinerários os remetem a cursos no exterior e a casamentos arranjados. As viagens e visitas entre familiares os conduzem a outras localidades e países. Eles costumam indicar a existência de 'pedaços da família' em outros lugares. Essa multiplicidade de itinerários é reconhecida pelos informantes como própria da família árabe ou de palestinos em diáspora.

Do ponto de vista analítico, as situações descritas permitem entender os processos que conduziram ao reconhecimento da identidade de origem e ao uso da identidade palestina como parte de um processo que ampliou o campo de possibilidades disponível para os migrantes traçarem destinos individuais e coletivos. Podemos assim verificar os nexos entre fenômenos locais e extralocais que conduziram a um processo de comunização no Chuí e que nos permitem entender as experiências de grupos minoritários não só em relação aos 'locais', mas também como forças que produzem outros efeitos, e outras viagens, a partir da revitalização da identidade de origem.

Denise Fagundes Jardim é doutora pelo PPGAS/M useu Nacional eProfessorado Departamento deAntropologiadaUFRGS. 


\section{NOTAS}

1 A identidade étnica é tratada, nos termos de Barth (1984), como um idioma que organiza e expressa relações sociais.

2 Em J ardim (2000), tratei da maneira como os entrevistados utilizam a noção de diáspora. O termo permite sintetizar uma 'qualidade' especial das famílias espalhadas em várias localidades. Os entrevistados salientam a vitalidade da linha paterna e sua capacidade de manter vínculos mesmo à distância. O termo é utilizado para sintetizar reflexões sobre as experiências dos entrevistados. Utilizam-se de noções de "família" (brasileira, árabe, italiana) a partir da reflexão sobre o que observam na sua própria parentela.

3 O Chuí tem cerca de 3.600 habitantes registrados no censo do IBGE de 1996. Um levantamento de 1997 realizado pela prefeitura registrou 6.564 habitantes. O Chuí é a segunda cidade de fronteira que concentra maior número de estrangeiros residentes. $\mathrm{O}$ número de estrangeiros pode ser estimado pela procedência registrada na Polícia Federal: até 1999, somavam-se 134 jordanianos e 13 palestinos, mas a maioria de estrangeiros é, de fato, uruguaia. Além disso, a afirmação como palestino engloba migrantes e filhos de migrantes nascidos no Brasil. As estimativas dos entrevistados indicam cerca de duzentos palestinos. O dado impreciso permite um uso flexível por parte dos entrevistados, de acordo com o debate: sobre o perigo de sua presença, ou ponderando sobre sua representatividade na política local.

4 No Chuy (uruguaio), os equipamentos públicos remetem à criação da República Oriental Uruguai no final do século XIX, e visavam suplantar ações de contrabando e o uso das fronteiras como locais de invernada do gado pelos brasileiros.

5 Para arabistas como Bernard Lewis (1982), o termo árabe é uma palavra obscura de raiz semítica - aribi -, significando "Ocidente", usada pela primeira vez pelos habitantes da Mesopotâmia referindo-se aos povos do Ocidente do vale do Eufrates. Embora a etimologia seja discutível em termos lingüísticos, a expressão foi usada primeiramente como uma atribuição e não como autodenominação para designar os povos nômades e, no período posterior, com Maomé, designava os não convertidos versus os "povos do livro". Essas denominações são classificações tidas e vistas pelos entrevistados desta pesquisa como tipos raciais e que indicam áreas e territórios de origem. Do ponto de vista analítico, o termo árabe é tomado como uma classificação produzida social e historicamente. Utilizado primeiramente no século VII para designar os 'outros' povos, vistos como nômades e que não conheciam o livro sagrado, é uma atribuição que reduz a diversidade dos 'outros' e que impõe uma classificação. Os termos árabe e palestino são tomados aqui como classificações sociais. São uma produção social e histórica, mesmo que, do ponto de vista nativo, elas busquem definir qualidades comuns e eternizar-se como de longa duração.

6 Truzzi (1997) é um trabalho fundamental sobre os itinerários de migrantes de origem árabe para o Brasil e sobre as condições sociais da reinvenção de sua identidade.

7 Sobre as "gerações" de migrantes ver Sayad (1977). O autor demonstra uma clivagem entre as gerações de migrantes através da forma como expressam sua experiência e as expectativas de inserção na França. A diferença entre "primeira" e "segunda geração" refere-se a formas de inserção nas relações locais que não correspondem, simplesmente, a um lugar de nascimento, no caso, França ou Argélia.

8 Em árabe, sanaud significa voltaremos. Na América Latina, os núcleos do sanaud foram incentivados pelos escritórios da OLP no início dos anos 80 com a finalidade de mobilizar os filhos de palestinos a atuar na política local como divulgadores da causa palestina, inclusive perante os migrantes.

9 A esse respeito, ver Aburish (1988), no estudo sobre a experiência de famílias palestinas desde 1917. Demonstra, através da trajetória de sua família, um microcosmo exemplar sobre os distúrbios no Oriente Médio e os reflexos em sua família, tentando traçar a continuidade frente a transformações e deslocamentos. Abdulrahim (1992-1993) analisa os palestinos na Alemanha e o papel fundamental do Islamismo (como parte de uma bagagem cultural), que garante a continuidade do grupo e forja fronteiras simbólicas com a sociedade abrangente em Berlim.

10 A esse respeito ver J ardim (2001). As relações familiares e conflitos na 'família árabe' são analisados nesse trabalho no sentido proposto em Bourdieu: “... é preciso analisar todo o trabalho simbólico e prático que tende a transformar a obrigação de amar em disposição amorosa e a dotar cada um dos membros da família de um 'espírito de família' “ (1997:129). 
11 É sob a perspectiva dos grupos minoritários que percebemos que os migrantes nas sociedades que os recebem acabam envolvidos por outros jogos identitários, muito diversos de acordo com as políticas estatais que visam assimilá-los e que, em vistas da assimilação aos nacionais, elegem alguns indicadores como base para avaliação dessa assimilação. Os grupos minoritários têm sido referidos na sua capacidade de evocar singularidades de origem através de um repertório que faz referência aos temas prioritários dos Estados nacionais, recriando a pertinência da raça, do território de origem, um idioma comum, uma religião específica, uma memória da migração - adensando elementos díspares em um mesmo fluxo da narrativa.

12 A idéia de casamentos arranjados tem conferido exotismo àqueles que são reconhecidos como muçulmanos ou árabes. Tal exotização dos migrantes ou muçulmanos não percorre as formas como os sujeitos são disponibilizados para tal arranjo. Tudo se passa como se este arranjo fosse, por princípio, desejável e normal para os nativos. De uma parte, isto significa uma filiação a um conceito de cultura como algo inscrito e plenamente disponível para todos os sujeitos, prescindindo de suportes e mecanismos sociais que mostrem sua pertinência; de outro lado, converge para uma noção possível de tradição como algo permanente e atemporal, segundo a qual não poderíamos demostrar a apropriação e a circulação de arranjos, pois acabaríamos destituindo a autenticidade de tal arranjo e dos sujeitos envolvidos.

13 Barth (1989) faz referência a forças centrípetas que conduzem a identidade social, referindo-se a conflitos estruturais próprios de um grupo ou sociedade. No caso analisado, as diferenças entre gerações produzem dissensos e suas resoluções reforçam diferenças geracionais como próprias do seu mundo social.

14 Utilizo a noção de Gilberto Velho (1994) para pensar o campo de possibilidades dos entrevistados para produzir projetos individuais e coletivos. Ver J ardim (2001)

15 Uma das acusações freqüentes por parte dos 'locais' é que os árabes "só namoram" com as brasileiras, mas casam com as árabes que nem conheciam, casamentos tratados entre familiares. A acusação revela as suspeitas que recaem sobre sua situação de 'estrangeiros' nas relações locais e também a exotização dos árabes em função dos casamentos arranjados. 


\section{REFERÊNCIAS BIBLIOGRÁFICAS}

ABDULRAHIM, Dima. 1992-1993. “Islam in a North European Setting: Palestinians in Berlin. In: Ziba Mir-Hosseini (org.), Islamic Family Law: Ideals \& Realities. London: Cambridge Anthropology, 16:2, pp.97-108.

ABURISH, Said. 1988. Children of Bethany. The Story of a Palestinian Family. London: I.B. Tauris \& Co. Ltd..

BARTH, F. 1984. "Problems of Conceptualizing Cultural Pluralism, with Illustrations from Somar, Oman”. In: D. MayburyLewis (ed.), The Prospects for Plural Societies. American Ethnological Society.

. 1989. "The Analysis of Culture in Complex Societies". Ethnos 54 (3/4).

BOURDIEU, P. 1996. Razões Práticas. Sobre a teoria da ação. Campinas: Papirus.

ELIAS, Norbert. 1994. The Established and the Outsiders: A Sociological Enquiry into Community Problems. London: Sage.

GELLNER, Ernest. 1983. Nation and Nationalism. London: Basil Blackwell.

J ARDIM, Denise F. 1999. “'Quer comprar roupa feita?' A Negociação de Identidades Sociais de Imigrantes Palestinos”. In: História em Revista vol. 5. Pelotas: UFPEL.

. 2000. "Diásporas, Viagens e Alteridades: As Experiências Familiares dos Palestinos no Extremo-sul do Brasil". In: Horizontes Antropológicos no 14. Porto Alegre: UFRGS/PPGAS.

2001. Palestinos no Extremo Sul do Brasil: Identidade Étnica e os Mecanismos Sociais de Produção da Etnicidade.

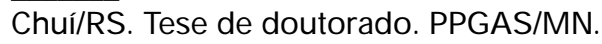

LEWIS, Bernard. 1982. Os árabes na história. Lisboa: Editorial Estampa.

OLIVEIRA, J oão Pacheco de. 1994. “A Viagem da Volta; Reelaboração Cultural e Horizonte Político dos Povos Indígenas do Nordeste". In: Atlas das terras Indígenas/Nordeste. Rio de J aneiro: PETI/Museu Nacional/UFRJ , pp. V-VIII.

SAID, Edward. 1990. Orientalismo. O Oriente como Invenção do Ocidente. São Paulo: Cia. das Letras.

SAYAD, Abdelmalek. 1977. “Les Trois 'Ages' de I’Emigration Algerienne en France”. Actes de la Recherche no 17, pp. 5979.

THOMAS, W. I. \& F. ZNANIECKI. 1974. The Polish Peasant in Europe and Americans. Vol. 2, Part III. New York: Octagon Books.

TRUZZI, Oswaldo Mário Serra. 1997. Patrícios. Sírios e Libaneses em São Paulo. São Paulo: Hucitec.

TURNER, Victor. 1974. Dramas, Fields, and Metaphors. Symbolic Action in Human Society. London: Cornell University Press.

VELHO, Gilberto. 1994. Projeto e Metamorfose. Antropologia das Sociedades Complexas. Rio de J aneiro: Zahar. 
RESUMO

Este artigo apresenta reflexões sobre a identidade palestina e os processos sociais de construção de identidade étnica observados no extremo sul do Brasil. O trabalho de campo foi realizado entre 1996 e 2000 envolvendo entrevistas, observação participante e análise de documentos produzidos pelos entrevistados, que vivem no Chuí (Rio Grande do Sul), na fronteira entre Brasil e Uruguai.

Os estudos sobre migrações recentes possibilitam refletir sobre os processos de recriação de tradições e sobre as negociações sociais que agem no sentido de configurar um grupo étnico. Nesse artigo, indico as situações sociais e negociações que configuram a identidade social e a produção de uma "comunidade árabe" como um grupo minoritário no Sul do Brasil. Focalizo as viagens e as ações coletivas empreendidas do início da década de 80 até o fim dos anos 90 e o reconhecimento do Estado Palestino pela ONU. Estabeleço alguns dos nexos entre ações locais e extralocais e de que maneira contribuíram para configurar uma autodenominação e o reconhecimento dos migrantes como palestinos.

\section{ABSTRACT:}

This article is about Palestinian identity and social processes involving the construction of ethnic identity in the extreme South of Brazil. It focuses on the recreation of traditions and the social dealings that shape that specific ethnic group. The ethnographic part is developed from direct and participant observation as well from the analysis of documents produced by interviewees living in the town of Chuí, in the state of Rio Grande do Sul, on the border between Brazil and Uruguay. This study analyzes expressions of social identity relating to the identification of members of the group as Palestinians. It deals with the processes and social mechanisms which give vitality to this ethnic identity and its experience as a minority group. 